\title{
O IMAGINÁRIO COLETIVO DA EQUIPE DE ENFERMAGEM SOBRE A INTERRUPÇÃO DA GESTAÇÃO
}

\author{
Miriam Tachibana, Fabiana Follador e Ambrosio, Daniel Beaune e \\ Tânia Maria José Aiello Vaisberg
}

\author{
Miriam Tachibana \\ Pós-doutoranda em \\ Psicologia Clínica \\ pela Universidade \\ de São Paulo e \\ pela Université \\ de Paris $\mathrm{X}-$ \\ Nanterre, com bolsa \\ Fapesp. Doutora \\ em Psicologia, \\ Ciência e Profissão, \\ pela Pontifícia \\ Universidade \\ Católica de \\ Campinas, com \\ bolsa brasileira \\ do CNPq, doutora \\ em Psicologia \\ pela Université \\ Charles de Gaulle \\ Lille 3, com bolsa \\ sanduíche da Capes.
}

$\begin{array}{ll}\text { Fabiana Follador e } & \text { Tânia Maria José Aiello } \\ \text { Ambrosio } & \text { Vaisberg } \\ \text { Doutora em } & \text { Professora } \\ \text { Psicologia, } & \text { livre docente } \\ \text { Ciência e Profissão } & \text { e orientadora } \\ \text { pela Pontifícia } & \text { de mestrados e } \\ \text { Universidade } & \text { doutorados do } \\ \text { Católica de } & \text { Programa de } \\ \text { Campinas, com } & \text { Pós-Graduação } \\ \text { bolsa do CNPq. } & \text { em Psicologia da } \\ & \text { PUC-Campinas } \\ \text { Daniel Beaune } & \text { e do Instituto de } \\ \text { Professor doutor no } & \text { Psicologia na USP, } \\ \text { curso de Psicologia } & \text { coordenadora da } \\ \text { da Université } & \text { Ser e Fazer: Oficinas } \\ \text { Charles de Gaulle } & \text { Psicoterapêuticas } \\ \text { Lille 3 e orientador } & \text { de Criação e } \\ \text { de mestrados e } & \text { presidente da NEW } \\ \text { doutorados na } & \text { (Núcleo de Estudos } \\ \text { Université Paris- } & \text { Winnicottianos de } \\ \text { Diderot - Paris 7. } & \text { São Paulo). } \\ & \end{array}$

RESUMO: Objetivamos investigar o imaginário coletivo de enfermeiras sobre a mulher cuja gravidez foi interrompida, já que o trabalho da enfermagem envolve, além de cuidados técnicos, proximidade inter-humana em situação de fragilidade emocional. Entrevistamos individualmente 16 profissionais, usando o Procedimento Desenhos-Estórias com Tema. Após cada entrevista, redigimos narrativas transferenciais que, com os desenhos-estórias, foram consideradas psicanaliticamente, visando a produção interpretativa de campos de sentido afetivo-emocional. Observamos três campos que permitem a compreensão de que a gravidez interrompida é associada a fantasias de maldade e falta de amor materno, o que pode estar relacionado a eventuais dificuldades no cuidado a estas pacientes.

Palavras-chave: Enfermagem, gravidez, imaginário coletivo, procedimento de desenhos-estórias com tema 
ABSTRACT: The collective imaginary of the nursing staff about pregnancy's interruption. We aimed at investigating the collective imaginary of nurses about women whose pregnancy was interrupted, since nursing's work involves technical care and human's proximity in situation of emotional fragility. We interviewed 16 professionals, using the Drawing Stories with Theme. After each interview, we wrote psychoanalytical narratives that, with the drawing stories, were psychoanalytically considered, in order to produce, by interpretation, fields of affective and emotional sense. We observed three fields that allow the comprehension that the interrupted pregnancy is associated with fantasies of evil and lack of maternal love, which may be related to possible difficulties in caring those patients.

Keywords: Nursing, pregnancy, collective imaginary, procedure drawing stories with theme.

\section{O FENÔMENO DA INTERRUPÇÃO DA GESTAÇÃO}

Observamos que a literatura psicológica focada no fenômeno da interrupção da gestação detém-se na experiência emocional da mulher cuja gravidez foi interrompida, constituindo conhecimento que pode ser clinicamente útil, como os trabalhos de Gesteira, Barbosa e Endo (2006) e Benute, Nomura, Pereira, Lucia e Zugaib (2009). Como a maioria desta população tende a vivenciar uma gravidez subsequente em pouco tempo (VIDAL, 2008, 2010), entendemos que tais estudos configurariam uma atenção psicológica clínica não apenas à mulher, mas, também, ao bebê que poderá vir a ter e que dela dependerá.

Sabemos que, segundo os padrões da cultura ocidental, as mães são vistas como aquelas que exercem função essencial no desenvolvimento emocional das crianças, sendo que seu desempenho materno dependeria, como parece julgar o senso comum, exclusivamente de características “internas” da mulher. No presente estudo, entretanto, partimos da compreensão de que toda manifestação humana, incluindo a maternagem, emerge em condições concretas, históricas, culturais, sociais e econômicas (BLEGER, 1963; FERRARI e PICCININI, 2010), sejam elas a familiar, a conjugal, a laboral ou a hospitalar. Dentre os ambientes sociais que sustentam a maternagem, optamos por focalizar o hospitalar, constituído essencialmente pela equipe de enfermagem obstétrica, vale dizer, enfermeiros, técnicos e auxiliares de enfermagem. Essa escolha por entrevistar esse coletivo justifica-se pela óbvia importância do ambiente hospitalar, apontado, 
por pais que sofreram perdas gestacionais, como fundamental na elaboração de vivências de enlutamento (RODRIGUES e HOGA, 2005; GANIÈRE e FAHRNI-NATER, 2009).

Winnicott (1957) esteve tão atento à influência da equipe hospitalar na relação que a mãe estabeleceria com seu recém-nascido que, diferentemente dos teóricos de sua época, ao invés de debruçar-se apenas sobre os significados inconscientes de determinados sintomas das gestantes, optou por produzir outro tipo de conhecimento psicanalítico:

\begin{abstract}
“De que forma a psicanálise associa-se ao tema da obstetrícia? (...) A psicanálise está começando a projetar luz sobre todos os tipos de anomalias, tais como a menorragia, os abortos sucessivos, a náusea e o vômito no início da gravidez (...) Muito tem sido escrito sobre estes distúrbios psicossomáticos. Aqui, no entanto, estou preocupado com outro aspecto da contribuição psicanalítica: tentarei indicar, em termos gerais, o efeito das teorias psicanalíticas sobre as relações entre o médico, a enfermeira e a paciente (...)” (WINNICOTT, 1957, p.61-62)
\end{abstract}

Assim, do mesmo modo que Winnicott teorizava acerca da importância de um ambiente suficientemente bom, encarnado nos cuidados maternos, ao desenvolvimento das potencialidades inatas do bebê, entendemos que a constituição de um ambiente hospitalar suficientemente bom seria essencial para a mulher sentir-se emocionalmente sustentada e capaz de fazer o mesmo em relação ao bebê que poderá vir a ter (AIELLO-VAISBERG e TACHIBANA, 2008).

À medida que todo ser humano demanda um ambiente suficientemente bom, independentemente da etapa evolutiva em que se encontra, entendemos que a constituição de um ambiente hospitalar suficientemente bom seria valiosa também para a própria atuação da equipe de enfermagem. Afinal, estudos realizados com equipes hospitalares demonstram que tais grupos vivenciam intensa angústia, ao lidar cotidianamente com o sofrimento físico e emocional de seus pacientes (LUNARDI et al., 2004; FERICELLI, 2008).

Estamos, desse modo, de pleno acordo com Campos (2003, p.41):

“Desde a década de 70 (...), os profissionais de saúde vêm sendo estimulados a funcionarem como suportes sociais para seus pacientes, seja individualmente, seja em equipe (...). Seu uso vem se difundindo, seja em ambulatórios, hospitais ou ambientes comunitários (...). Por outro lado, se considerarmos o estresse cotidiano em que vivem tais profissionais no contato direto com o sofrimento e a morte, fácil é imaginar que, também eles, estejam vulneráveis a doenças (...). Observa-se que é extensa a literatura sobre grupos de suporte voltados para pessoas e situações de 
doença, mas poucos são os trabalhos que enfocam os profissionais da saúde, não enquanto 'cuidadores', mas enquanto pessoas demandando 'cuidados'”

Podemos supor que esta escassez de trabalhos investigativos sobre a vivência emocional da equipe de enfermagem em seu cotidiano de trabalho esteja relacionada a uma dificuldade, por parte da comunidade científica, em concebê-la como um grupo social que demanda atenção psicológica. Tal obstáculo pode estar ligado tanto à postura tecnicista e racional dos profissionais, que não transparece seu próprio sofrimento emocional, quanto a um imaginário social em relação aos profissionais de enfermagem, os quais seriam pessoas "naturalmente" cuidadoras, no sentido de terem uma disponibilidade emocional para a devoção e o cuidado (PESSINI, 2002; SADOCK, 2003; ELIAS e NAVARRO, 2006).

“A enfermagem está ligada, desde suas origens, à noção de caridade e devotamento, sendo seus primeiros executores pessoas ligadas à igreja, ou leigos praticando a caridade. Esse fato imprimiu marcas que perduram até hoje e se explicitam na concepção de enfermagem de alunos e enfermeiros. (...) A ideologia que perpassa a profissão desde sua origem significa abnegação, obediência, dedicação. (...)” (ELIAS e NAVARRO, 2006, p.518)

Dessa maneira, a realização deste estudo visa a produzir conhecimento que possa contribuir para a identificação dos aspectos emocionais envolvidos no trabalho da equipe de enfermagem, que possa ser empregado no favorecimento da constituição de um ambiente hospitalar suficientemente bom, que beneficiaria tanto a mulher que sofreu a interrupção da gestação quanto o bebê que poderá ter futuramente, bem como a equipe de enfermagem obstétrica.

\section{INVESTIGANDO O IMAGINÁRIO COLETIVO DA EQUIPE DE ENFERMAGEM}

Em nosso grupo de pesquisa ${ }^{1}$, temos realizado estudos focados nos aspectos afetivo-emocionais subjacentes às condutas humanas, dessa maneira, intencionando produzir conhecimento sobre as motivações de indivíduos e coletivos que estariam sustentando práticas estereotipadas. A partir daí, desenvolvemos o conceito de "imaginário coletivo" entendido, a partir do conceito de "conduta" de Bleger (1963), como manifestações simbólicas de subjetividades grupais, ou seja, as imagens, crenças e emoções que um determinado grupo social produz em relação a um fenômeno (AIELLO-VAISBERG e MACHADO, 2008).

\footnotetext{
${ }^{1}$ Grupo de pesquisa CNPq “Atenção psicológica clínica em instituições: prevenção e intervenção".
} 
Assim, com o intuito de investigar o imaginário coletivo da equipe de enfermagem acerca do fenômeno da interrupção da gestação, abordamos uma equipe de enfermagem obstétrica de um hospital-maternidade, do interior do estado de São Paulo. Participaram dezesseis mulheres, das quais quatro enfermeiras, dez técnicas e quatro assistentes de enfermagem, que atuavam nos plantões matutino, vespertino e noturno.

As entrevistas foram realizadas individualmente, no próprio ambiente hospitalar, seguindo um enquadre clínico, apropriado para o estudo de imaginários coletivos, denominado "entrevista individual para abordagem da pessoalidade coletiva” (ÁVILA, TACHIBANA e AIELLO-VAISBERG, 2008). Tal configuração clínica pressupõe o uso de recursos mediadores dialógicos visando a facilitar a expressão emocional dos participantes, seguindo o paradigma das consultas terapêuticas, em que Winnicott (1968) fazia uso do jogo do rabisco para favorecer a expressão emocional significativa de seus pacientes.

Neste estudo, foi empregado o Procedimento Desenhos-Estórias com Tema (AIELLO-VAISBERG, 1999), convidando as participantes a elaborarem um desenho sobre o tema "uma mulher que sofreu interrupção da gestação" e a inventarem, a seguir, uma história sobre a figura desenhada. Ao final, as participantes eram solicitadas a atribuírem um título à produção gráfica.

Após a realização das entrevistas, uma das pesquisadoras ${ }^{2}$ redigiu narrativas transferenciais, tendo em vista registrar o acontecer clínico. Trata-se de uma estratégia metodológica que temos usado, tanto em pesquisas sobre imaginários coletivos como em investigações sobre eficácia clínica ou potencialidade mutativa de enquadres de atendimento psicológico (GRANATO e AIELLO-VAISBERG, 2004; AIELLO-VAISBERG e MACHADO, 2005; AIELLO-VAISBERG et al., 2009).

Assim, por meio do método psicanalítico, a entrevistadora redigiu os relatos das manifestações das participantes, bem como a comunicação de suas impressões e sentimentos contratransferenciais, vivido em cada encontro. Posteriormente, o corpus formado pelo conjunto das dezesseis narrativas psicanalíticas e dos dezesseis desenhos-estórias foi apresentado aos integrantes do grupo de pesquisa, todos com formação psicanalítica, com a finalidade de provocar múltiplos olhares a fim de favorecer uma compreensão emocional abrangente e aprofundada.

"A apresentação [da narrativa] suscitará narrativas alternativas. Estas não se referirão
evidentemente ao acontecer primeiro, tomado como imaginário, do encontro inicial,
mas ao que poderá ser acrescentado, transformado, criado/encontrado na narrativa
primeira. Enfim, a narrativa não pede que o outro se cale — ou se pronuncie diante

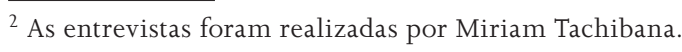


de um erro, de uma falha —, mas sim que prossiga, que, sentindo-se provocado, no sentido etimológico do termo latino, possa fazer suas associações, possa tecer suas considerações. (...)” (AIELLO-VAISBERG e MACHADO, 2005, p.7)

Desse modo, fazendo uso do método psicanalítico, o grupo de pesquisadores deixou-se impressionar emocionalmente pelo material clínico para buscar "campos de sentido afetivo-emocional". Trata-se de conceito que foi articulado repensando e retomando a "Teoria dos Campos” de Herrmann (2001) e o conceito de "conduta" de Bleger (1963), que permitem conceber os campos de sentido afetivo-emocional como conjunto de regras lógico-emocionais que sustentariam as condutas.

\section{OS CAMPOS DE SENTIDO AFETIVO-EMOCIONAL DO IMAGINÁRIO}

A partir do encontro com o material, foram captados três campos de sentido afetivo-emocional: "Fim do mundo", "Enlouquecimento" e "Monstruosidade”.

Em relação ao campo “Fim do mundo”, pudemos observar que todos os desenhos-estórias produzidos pelas participantes emergiram, como condutas, a partir deste substrato afetivo-emocional. Trata-se de um inconsciente relativo regido pela crença de que a interrupção da gestação consistiria em evento de caráter apocalíptico, no sentido de que a morte de um bebê colocaria em risco a própria existência do mundo. Tratar-se-ia de uma equação simbólica, na qual parte e todo se confundiriam, o que, para alguns autores, indica esferas imaginárias de marcada profundidade (MATTE-BLANCO, 1988). O trecho de uma das narrativas cabe aqui como ilustração:

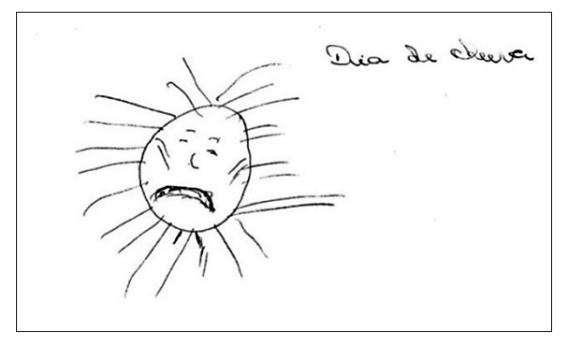

"Desenhei este sol morrendo, porque é assim que vejo a gravidez interrompida. A gente tem sempre certeza de que o sol vai nascer, no dia seguinte, não é? É algo que já é tão esperado e natural que a gente nem para para pensar que pode ser que ele não nasça. Para mim, gravidez sempre termina em nascimento: 0 bebê é feito para nascer, e não para morrer. Quando um bebê morre, é como se o sol estivesse morrendo também... É por isso que escolhi trabalhar em obstetrícia: porque queria ver bebês nascendo e mães renascendo junto com seus filhos...”. 
Um aspecto bastante interessante foi o de que, neste campo afetivo-emocional, pudemos observar a tentativa, nas produções, de detectar os sentimentos das gestantes visando a diferenciar aquelas que sofrem verdadeiramente com a perda de outras que estariam aliviadas por terem se livrado do bebê. Estas duas alternativas permitiram que o material se organizasse em dois grupos de manifestações imaginativas: um relacionado à mulher que sofreu uma interrupção espontânea da gravidez, configurando campo de sentido afetivo-emocional intitulado "Enlouquecimento"; e outro, denominado "Monstruosidade", que corresponderia às situações em que a mulher a provocou.

O campo "Enlouquecimento” organiza-se ao redor da regra lógico-emocional de que a interrupção espontânea da gestação lança a mulher numa agonia enlouquecedora. Este campo afetivo-emocional, subjacente a oito das produções gráficas, pode ser ilustrado com o trecho narrativo a seguir:

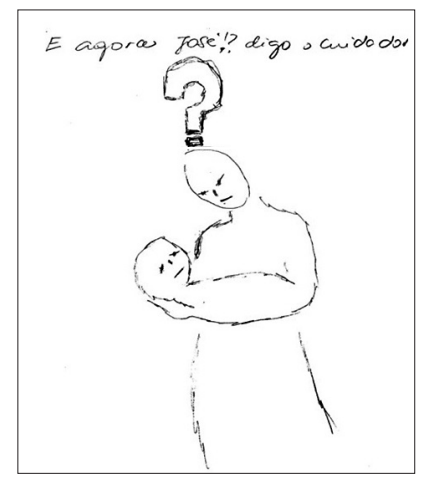

Após dizer-me que o ponto de interrogação representava a multiplicidade de condutas que poderiam ser assumidas por uma mulher que perdeu o seu bebê, o que tornava difícil a tarefa de descrevê-la para mim, a participante contou-me a seguinte história: "Teve uma vez que uma mãe, que tinha perdido o bebê, pediu pra segurar, no colo, o bebê de outra paciente que estava internada na enfermaria. Isto causou um choque para toda equipe e muita gente ficou pensando que ela havia enlouquecido. Só depois que pediram para que voltasse pro quarto que entendi que ela só queria segurar um bebê. Ela sabia que não era o dela, mas queria ver como seria".

Perguntei, então, se esta era a paciente que havia desenhado, para mim. A participante olhou para seu desenho e respondeu: "Não sei... Sabe que, na hora em que estava fazendo o desenho, não pensei em nenhuma paciente especificamente, mas pode ser que seja ela, sim. Aquela imagem dela mal conseguindo andar, chorando e pedindo para segurar o bebê de outra mãe, foi bem forte, para mim...”.

Observamos que este imaginário de que a mulher estaria condenada a um sofrimento eterno esteve associado à crença de que ela nutriria um secreto desejo de interrupção da gestação. Assim, este campo da agonia enlouquecedora corres- 
ponderia a uma punição ao desamor que, mesmo não motivando atos voluntários de provocação de aborto, ter-se-ia manifestado por um caminho psicossomático, interrompendo a vida do bebê. Tal configuração pode ser apreciada a seguir:

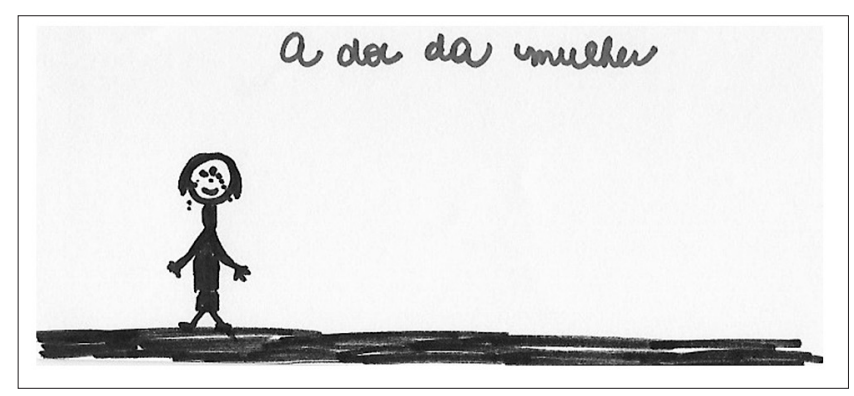

"Esta mulher que desenhei está chorando porque perdeu o bebê. A gente vê, aqui, que as mulheres que perdem o bebê têm reações muito diversas: umas choram muito e você vê, daí, que essas queriam muito aquela gravidez; outras ficam mais caladas, sérias, e você percebe que aquela gravidez não era tão querida. Talvez a interrupção até tenha sido provocada, sabe?".

Perante este comentário da entrevistada, questionei: "Mas e esta aqui que você desenhou? Ela está chorando, mas também está sorrindo". A participante respondeu: "É, aqui ela está fazendo as duas coisas, né? Mas ela realmente queria a gravidez. E está sorrindo porque o seu bebê era muito malformado e não teria uma vida muito digna... Neste caso, foi melhor para o bebê que acabasse falecendo dentro da mãe dele...”.

Por sua vez, o campo “monstruosidade” define-se pela regra lógico-emocional que relaciona a interrupção da gestação a um ato hediondo, perpetuado por uma mulher de caráter insensível e cruel. Este inconsciente relativo, subjacente a seis das produções gráficas, manifesta-se, por exemplo, no trecho seguinte:

Quando perguntei à entrevistada como se sentia ao atender uma paciente que teve a sua gestação interrompida, respondeu-me: "Procuro fazer com que ela sofra o mínimo possível. Sempre tomo o cuidado de não deixar uma mãe que perdeu o bebê junto com uma mãe que está, ali, internada com o bebê ao lado. Hoje, quando cheguei no hospital e vi que tinha uma mãe esperando para ser internada, pois tinha o diagnóstico de óbito fetal, fui olhar, na minha listagem, se tinha alguma outra paciente que estava internada, aqui, sem o bebê. Daí, vi que tinha uma sozinha, porque o bebê dela está na UTI neonatal. Juntei as duas no mesmo quarto, né? Só que, mais tarde, ouvi bronca da minha chefe: ela veio brigar comigo porque a mãe que estava sozinha, no quarto, é uma paciente que tentou provocar o aborto da gravidez, mas não conseguiu e seu bebê nasceu prematuro e cheio de problemas. Acabei juntando, sem saber, uma mãe que perdeu o bebê e outra que queria ter perdido, entendeu? E esta mulher, como não conseguiu interromper a gravidez, acabou prometendo dar o bebê para um casal...”. 
Notamos que este imaginário que associa a mulher que provocou a interrupção da gravidez a um ser monstruoso esteve, em três produções gráficas, associado ao bebê morto. Assim, haveria a crença, por parte da equipe de enfermagem, de que a malformação — que não raro acompanha os bebês natimortos — seria um efeito da monstruosidade materna, como se o bebê denunciasse a sua feição desumana. Para ilustrar este fenômeno, segue o material clínico:

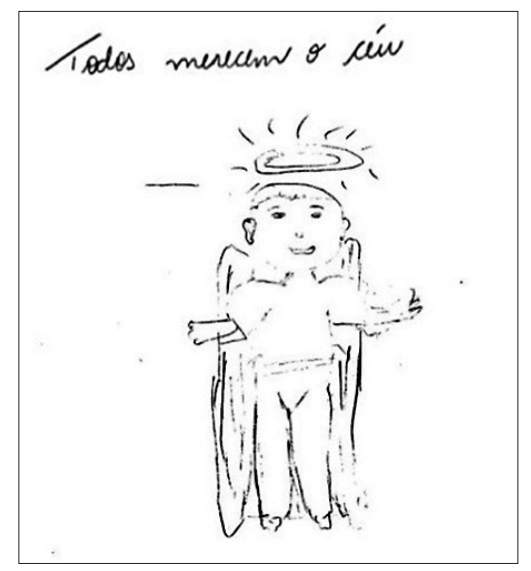

Quando pedi para que me contasse uma história associada ao desenho, disse: "Acredito que todos, principalmente as crianças, quando morrem, vão pro céu. Esta criança que desenhei é um bebê que não teve a oportunidade de viver aqui na Terra".

A entrevistada narrou, então, uma situação em que foi acompanhar uma paciente, até a geladeira, para que conhecesse seu bebê falecido: "Eu sabia que o bebê tinha múltiplas malformações, porque o pessoal que estava no parto já tinha comentado. Daí, quando a mãe pediu para que a acompanhasse, já sabia que veria algo difícil. Mas não imaginava que fosse tanto... Era um bebê que não tinha pernas e braços (os pés e as mãos partiam direto do corpo); tinha uma cabeça grande (maior que o tamanho do corpo); estava com o cérebro exposto; tinha duas genitálias...”.

\section{CONSIDERAÇÕES FINAIS}

A presente investigação permitiu detectar crenças inconscientes no coletivo de enfermagem obstétrica, de acordo com as quais a ocorrência de interrupção da gestação carregaria um sentido de devastação da vida e da humanidade. Assim, se, no imaginário socialmente predominante acerca da maternidade, há crenças de que toda mulher amaria incondicionalmente seus filhos e a de que cada recém-nascido seria símbolo de vida e esperança, aquele que sai morto do ventre materno denunciaria um estado catastrófico. 
A morte do bebê é imaginariamente atribuída à mãe, seja porque provocou a interrupção, seja porque nutriu sentimentos de rejeição em relação ao filho. Considerada culpada, em registros imaginários profundos, a mulher deixa de ser concebida como merecedora de sentimentos de compaixão, solidariedade e empatia. Vemos, dessa maneira, que, malgrado sua formação profissional específica, a equipe de enfermagem sustenta um imaginário, provavelmente compartilhado pela sociedade em geral, de que a interrupção da gravidez equivaleria a um ato tão destrutivo que seria emocionalmente incompatível com uma motivação espontânea a prestar ajuda e cuidado. Trata-se de uma constatação a qual denota que, para que um trabalho de assistência hospitalar seja bem-realizado, os profissionais certamente precisam realizar movimentos psíquicos que permitam a superação da reação negativa imediata para considerarem tais mulheres como pacientes, no sentido preciso da palavra.

Tais considerações impelem a reflexões atinentes à necessidade e às possibilidades de intervenção dos psicólogos clínicos, que poderiam auxiliar os profissionais de saúde a elaborarem os sentimentos contraditórios que vivenciam diante da mulher que sofreu interrupção da gestação, à medida que a veem, simultaneamente, como pessoas que apresentam sintomas físicos que requerem tratamento e como aquelas que causaram, direta ou indiretamente, a morte de um inocente.

Vale ressaltar que o tipo de intervenção que este fenômeno requer é de caráter psicológico, não derivando, como creem alguns, de mera falta de conhecimento teórico. Não se trata, de modo algum, de substituir o imaginário dos profissionais por informação baseada em conceitos teóricos (SOUZA, ALENCASTRE e SAEKI, 2000; LOPES e LUIS, 2005), mas, sim, de realizar uma clínica psicológica voltada ao cuidado da equipe.

Dada a importância do substrato afetivo-emocional das condutas humanas, seria possível afirmar que o Programa Nacional de Humanização da Assistência Hospitalar do Ministério da Saúde ${ }^{3}$ carece de estratégias que favoreçam a consideração de tais aspectos vivenciais dos profissionais de saúde, privilegiando técnicas de desenvolvimento de habilidades interpessoais ou a apresentação teórica de temas relacionados ao cotidiano de trabalho. Apesar de o Programa de Humanização apontar para a necessidade de atenção à saúde mental dos profissionais, também com o intuito de oferecer cuidado indireto a seus pacientes, de maneira geral, os diversos pesquisadores mobilizados por este movimento acabam voltando-se ao tecnicismo, mesmo aqueles que o criticavam (DIMENSTEIN, 2004; BERNARDES e GUARESCHI, 2007; CARVALHO; SANTANA e SANTANA, 2009).

\footnotetext{
${ }^{3}$ Desde o ano 2000, o programa orienta diversas políticas públicas visando a "humanizar" o ambiente hospitalar, tanto do ponto de vista dos pacientes quanto dos profissionais.
} 
Partimos da concepção de que a transformação deste imaginário requer a criação de espaços onde estudantes e profissionais possam expressar seus sentimentos e crenças, tal como as participantes deste estudo puderam fazer ao longo das entrevistas. A provisão de atenção psicológica aparece como facilitadora da aproximação entre o que é pensado e o que é sentido, assim, permitindo uma integração destes aspectos experienciais e contribuindo tanto para a transformação de concepções estereotipadas quanto para a adoção de um fazer menos dissociado.

É justamente devido à preocupação em ressaltar o oferecimento de atenção psicológica a indivíduos e coletivos que se tem realizado investigações clínicas focadas na possibilidade de integração, na formação profissional, dos aspectos teóricos e técnicos aos afetivo-emocionais, destacando Aiello-Vaisberg (1999); Ribeiro, Tachibana e Aiello-Vaisberg (2008), Vitali e Aiello-Vaisberg (2006) e Baptista e Aiello-Vaisberg (2003). Incentivamos, desse modo, a realização de novos estudos, sejam relacionados à equipe de enfermagem obstétrica, sejam associados ao imaginário social prevalecente sobre a maternidade, de tal forma que, enquanto cidadãos, seja possível conviver com as variadas escolhas pessoais acerca da maternidade, favorecendo a criação de um mundo menos discriminatório e mais ético: um novo mundo, em vez do fim do mundo.

Recebido em 16/4/2012. Aprovado em 29/7/2012.

\section{REFERÊNCIĀS}

AIELLO-VAISBERG, T. M. J. (1999) Encontro com a loucura: transicionalidade e ensino de psicopatologia. Tese de Livre-Docência. Instituto de Psicologia, Universidade de São Paulo.

\& MACHADO, M. C. L. (2005) Narrativas: o gesto do sonhador brincante [CD-ROM], in Anais do Encontro Latino Americano dos Estados Gerais da Psicanálise, 4. São Paulo: Estados Gerais da Psicanálise. \& (2008) "Pesquisas psicanalíticas de imaginários coletivos à luz da teoria dos Campos”, in MONZANI, J. \& MONZANI, L. R. (Orgs.). Olhar: Fábio Herrmann, uma viagem psicanalítica. São Carlos: Editora Pedro e João Editores, p.311-324. , AYOUCH, T., CARON, R. \& BEAUNE, D. (2009)

"Les récits transferenciels comme présentation du vécu clinique: une proposition méthodologique”, in BEAUNE, D. (Org.), Psychanalyse, philosophie et art: dialogues. Paris: L’Harmattan, p.39-52.

\& TACHIBANA, M. (2008) "O ambiente hospitalar suficientemente bom: sustentação da preocupação materna primária”, in LANGE, E. S. N. (Org.). Contribuições à psicologia hospitalar: desafios e paradigmas. São Paulo: Vetor, p.145-162. 
Ávila, C. M. de, TACHIBANA, M. \& AIELLO-VAisBeRG, T. M. J. (2008) Qual é o lugar do aluno com deficiência? O imaginário coletivo de professores sobre a inclusão escolar. Paideia, 18, 155-164.

BAPTISTA, A. M. \& AIELLO-VAISBERG, T. M. J. (2003) “Agentes comunitários de saúde: o que não foi previsto. Uso de consultas terapêuticas coletivas na abordagem do sofrimento vivido pelos agentes comunitários de saúde", in AIELLO-VAISBERG, T. M. J. \& AMBROSIO, F. F. (Orgs.). Cadernos ser e fazer: apresentação e materialidade. São Paulo: Ipusp, p.105-120.

BENUTE, G. R. G., NOMURA, R. M. Y., PEREIRA, P. P., LUCIA, M. C. S. de \& ZUGAIB, M. (2009) Abortamento espontâneo e provocado: ansiedade, depressão e culpa. Revista da Associação Médica Brasileira, 55(3), 322-327.

BERNARDES, A. G. \& GUARESCHI, N. (2007) Estratégias de produção de si e a humanização do SUS. Psicologia, Ciência e Profissão, 27 (3), 462-475.

BLEGER, J. (1963) Psicologia da conduta. (E. D. O. DIEHL, Trad.). Porto Alegre: Artes Médicas.

CAMPOS, E. P. (2005) Quem cuida do cuidador: uma proposta para os profissionais da saúde. Rio de Janeiro: Editora Vozes.

CARVAlHO, D. B. de, SANTANA, J. M. \& SANTANA, V. M. de (2009) Humanização e controle social: o psicólogo como ouvidor hospitalar. Psicologia, Ciência e Profissão, 29(1), 172-183.

DIMENSTEIN, M. (2004) A reorientação da atenção em saúde mental: sobre a qualidade e humanização da assistência. Psicologia, Ciência $e$ Profissão, 24(4), 112-117.

ELIAS, M. A. \& NAVARRO, V. L. (2006) A relação entre trabalho, a saúde e as condições de vida: negatividade e positividade no trabalho das profissionais de enfermagem de um hospital-escola. Revista Latino-Americana de Enfermagem, 14 (4), 517-525.

FERRARI, A. G. \& PICCININI, C. A. (2010) Função materna e mito familiar: evidências a partir de um estudo de caso. Ágora, 13 (2), 243-257.

FERICELLI, F. (2008) Grossesse, naissance et transmission: la place d'un pédopsychiatre en maternité. Psychothérapies, 4 (XXVIII), 235-244.

GANIERI, J. \& FAHRNI-NATER, P. (2009) De l'enquête au soutien des parents endeuillés. Infokara, 24 (2), 55-60.

GESTEIRA, S. M. dos A., BARBOSA, V. L. \& ENDO, P. C. (2006) O luto no processo do aborto provocado. Acta Enfermagem, 19 (1), 462-467.

GRANATO, T. M. M. \& AIELLO-VAisBeRG, T. M. J. (2004) Tecendo a pesquisa clínica em narrativas psicanalíticas. Mudanças, 12 (2), 253-271.

HERRMANN, F. (2001) Introdução à Teoria dos Campos. São Paulo: Casa do Psicólogo.

LOPES, G. T. \& LUIS, M. A. V. (2005) A formação do enfermeiro e o fenômeno das drogas no estado do Rio de Janeiro - Brasil: atitudes e crenças. Revista Latino-Americana de Enfermagem de Ribeirão Preto, 13, 872-879.

LUNARDI, V. L., LUNARDI FILHO, W. D., SILVEIRA, R. S. DA, SOARES, N. V. \& LIPINSKI, J. M. (2004) O cuidado de si como condição para o cuidado dos outros na prática de saúde. Revista Latino-Americana de Enfermagem, 12 (6), 933-939. 
MATTE-BLANCO, I. (1988) Thinking, feeling and being. London: Routledg. PESSINI, L. (2002) Humanização da dor e sofrimento humanos no contexto hospitalar. Bioética, 10 (2), 51-72.

RIBEIRO, D. P. de S. A., TACHIBANA, M. \& AIELlO-VAiSBERG, T. M. J. (2008) A experiência emocional do estudante de psicologia na primeira entrevista clínica. Aletheia, 28, 135-145.

RODRIGUES, M. M. L. \& HOGA, L. A. K. (2005) Homens e abortamento espontâneo: narrativas das experiências compartilhadas. Revista da Escola de Enfermagem da USP, 39 (3), 258-267.

SADOCK, V. (2003) L'enjolivement de la réalité, une défense féminine? Étude auprès des auxiliaires puéricultrices. Travailler, 10(2), 93-106.

SOUZA, M. C. B. M. E, ALENCASTRE, M. B. \& SAEKI, T. (2000) Enfermeiros assistenciais das instituições psiquiátricas de Ribeirão Preto: caracterização, formação e atuação. Revista Latino-Americana de Enfermagem de Ribeirão Preto, 8 (5), 71-80.

VIDAL, M. (2008) Sobre a gravidez subsequente à morte perinatal - a síndrome da criança de substituição. Psicologia para América Latina, 13, $13-22$.

(2010). Gravidez após morte perinatal: sobre a relação da mãe com o bebê sobrevivente. Ciência e Saúde Coletiva, 15, 2799-2803.

VITALI, L. M. \& AIELLO-VAISBERG, T. M. J. (2006) “'Cada um sabe a dor e a delícia de ser o que é...”" O uso de consultas terapêuticas coletivas na abordagem do sofrimento emocional vivido pelos profissionais de saúde em ambulatórios de cuidados paliativos", in AIELLO-VAISBERG, T. M. J. \& AMBROSIO, F. F. (Orgs.). Cadernos Ser e Fazer: Imaginários coletivos como mundos transicionais. São Paulo: Ipusp, p.61-79.

WINNICOTT, D. W. (1957) "A contribuição da psicanálise à obstetrícia", in WINNICOTT, D. W. Os bebês e suas mães (J. L. CAMARGO, Trad.). São Paulo: Martins Fontes, p.61-71.

. (1968) “O jogo do rabisco”, in WINNICOTT, D. W., C., SHEPERD, R. \& DAVIS, M. (Orgs.). Explorações psicanalíticas D. W. Winnicott. Tradução de J. O. de A. ABREU. Porto Alegre: Artes Médicas, p.230-243.

\author{
Miriam Tachibana \\ mirita@uol.com.br \\ Fabiana Follador e Ambrosio \\ fabfoll@uol.com.br \\ Daniel Beaune \\ daniel.beaune@univ-lille3.fr \\ Tânia Maria José Aiello Vaisberg \\ aiello.vaisberg@gmail.com
}


